\title{
Micro-Mechanical Deformation Mechanisms in the Fracture of Hybrid-Particulate Composites Based on Glass Beads, Rubber and Epoxies
}

\author{
JONGHWI LEE ${ }^{1}$ and ALBERT F. YEE ${ }^{2}$ \\ Macromolecular Science and Engineering Program \\ The University of Michigan \\ 2300 Hayward. Ann Arbor, Michigan 48109
}

\begin{abstract}
Two tougheners, glass beads and carboxyl terminated butadiene acrylonitrile copolymer (CTBN), are used to toughen and stiffen an epoxy thermoset. Rubber-encapsulated glass beads are used and the hybrid particulate composites containing them are compared with those containing non-encapsulated glass beads. Within a certain range of composition, the rubber encapsulation is found to change the interactions between glass beads and CTBN particles, resulting in an increase in fracture toughness. The toughening effect is explained by the fact that the cavities of CTBN particles are larger in encapsulation systems than in non-encapsulation systems. As more CTBN particles are incorporated into glass bead filled epoxies, the cavitation/shear yielding mechanism of CTBN particles replaces the micro-shear banding mechanism of glass beads as the major micro-mechanical deformation. Rubber encapsulation seems to enable this transition of major micro-mechanical deformation to occur at a lower volume fraction of CTBN.
\end{abstract}

\section{INTRODUCTION}

$\mathrm{T}$ he brittleness of thermosets has imposed severe limitations on the application of thermoset polymers. As a consequence, efforts devoted to improving the toughness of thermosets have continued to grow for more than 40 years, and have established several successful toughening methods. The two most popular strategies for toughening thermosets are the incorporation of dispersed rubber particles and rigid inorganic particles into thermosets (1-3).

The existence of dispersed rubber particles on a microscopic scale can successfully improve the fracture toughness of thermosets (3). However, the improvement in toughness is usually accompanied by a detrimental effect, i.e., a decrease in modulus. On the other hand, toughening thermosets using inorganic particles does not give rise to this undesirable effect (1), so it appears to be superior to the other. In fact, the use of inorganic particles as tougheners could significantly improve both fracture toughness and modulus. However, the toughness increase is usually

\footnotetext{
'Current address: Department of Chemical Engineering and Materials Science. The University of Minnesota, 421 Washington Ave SE, Minneapolis, MN 55455. jong@cems.umn.edu

${ }^{2}$ To whom correspondence should be addressed. Fax 734-763-4788. afyee@engin.umich.edu
}

smaller than that by rubber particles (2). The hybridization of the two tougheners to both toughen and stiffen thermosets is considered in this paper.

Simple hybridization, which is the separate dispersion of two different kinds of particles in thermosets, has proven effective in both toughening and stiffening (4-12). Kinloch et al. (5) reported in their studies on the fracture behavior of CTBN/glass bead/epoxy composites that both the crack front bowing mechanism (13-16) and the cavitation/shear yielding mechanism (17-22) were active in the fracture of the hybrid composites. They were identified as the major sources of toughness for glass bead and rubber particle toughened epoxies, respectively. When the volume fractions of two tougheners were similar, the rubber particles were reported to be more effective in increasing the fracture toughness of composites. Thus, cavitation/ shear yielding was treated as the more effective mechanism.

Since more than two toughening mechanisms can operate together in the fracture of hybrid-particulate composites, synergistic effects are expected to result from the interplay of two (or more than two) mechanisms. In fact, there are several reports on this possible synergistic effect $(6,7,11,12)$. In these reports, synergistic effects have been observed and explained by using toughening mechanisms such as crack front bowing, crack bridging, and matrix shear yielding. 
The previous studies $(5-8,10-12)$ obviously show that the hybridization of tougheners can give more effective ways of improving the fracture toughness and modulus of thermosets. Yet, the fracture mechanisms of hybrid-particulate systems have not been extensively studied. In particular, the interactions between two tougheners and micro-mechanical deformations have not been thoroughly investigated. Since the crack front bowing mechanism (13-16) cannot identify energy dissipation routes (23-25), it seems difficult to understand the interplay of crack front bowing with other energy dissipating mechanisms. Furthermore, from our previous studies (23-25), the major energy absorption source in the fracture of glass bead filled epoxies was found to be micro-shear banding. Therefore, using this newly established mechanism is expected to allow us to better understand the interactions between glass beads and rubber particles as tougheners.

In the current study, CTBN particles and glass beads are used as tougheners in an epoxy matrix and the fracture behavior of resulting composites is investigated. In particular, micro-mechanical deformations occurring during fracture of the hybrid-particulate composites are studied to understand the interactions between particles. The hybrid-particulate composites containing glass beads encapsulated with a cured rubber are also prepared and their fracture behavior is compared with the simple (non-encapsulated) hybrid-particulate system.

The study on the encapsulated system is interesting because the previous reports on the effect of encapsulation (26-30) are controversial. Furthermore, the underlying mechanisms of effective toughening were not adequately illustrated in the former studies on encapsulated systems. Among the encapsulated systems used in the previous studies (26-30), the systems prepared by in-situ methods might have discrete rubber particles in the matrix (26-32). Thus, our encapsulated system prepared in the current experiment could be a well-controlled model of the systems prepared by in-situ methods.

\section{EXPERMMENTAL}

\section{Materials}

The glass beads used in these experiments are Speriglass $^{\circledR}$ A-glass beads (soda-lime) produced by Potters Industry Co. Their mean diameter is $27.9 \mu \mathrm{m}$, which is obtained from more than 150 size measurements using a transmitted light optical microscope (OM), Nikon Microphot II equipped with a SONY color video CCD camera, DXC-151A (768 $\times 493$ pixels). Before being used, they were cleaned using distilled water as described in references 23-25. The diglycidyl ether of bisphenol A (DGEBA) epoxide, DER $661^{\oplus}$, is a commercial resin of the Dow Chemical Co. The liquid rubber (CTBN) is Hycar $1300 \times 13^{\oplus}$ produced by the BFGoodrich Chemical Co. All other chemicals are obtained from the Aldrich Chemical Co. and used without further purification.
Rubber-encapsulated glass beads (0.5-LG) were prepared by the solution/evaporation technique $(33$, $34)$, as described in the previous reports (23-25). The rubbery material used (CDI adduct) was prepared from CTBN (Hycar $\left.1300 \times 13^{(}\right)$, DGEBA (DER 332), and isophoron diamine (IPD) (23-25). For the encapsulation of glass beads, it was dissolved in methylethylketone and mixed with glass beads (feed fraction of rubbery material $=0.5 \mathrm{wt} \%$ ). After complete evaporation, the rubbery material was completely cross-linked at $120^{\circ} \mathrm{C}$ for 12 hours, resulting in the formation of insoluble (stable) rubber layers around glass beads. Before the encapsulated glass beads were used in the next steps, large agglomerates were screened out using a $75 \mu \mathrm{m}$ sieve (mesh size = 200 ). The weight fraction of rubber layers was measured using thermal gravimetric analysis (TGA), and the size distribution analysis of encapsulated glass beads was performed using a Horiba CAPA-700 particle size analyzer as described in references 23-25. $0.5-\mathrm{LG}$ was found to have $0.55 \mathrm{wt} \%$ rubber layer $\mathrm{t} / \mathrm{r}$ $=0.45 \%$, where $t$ is the thickness of rubber layer and $\mathrm{r}$ is the mean radius of glass). The aggregation of glass beads is insignificant as can be found in references 23 and 25.

\section{Preparation of Composites}

The epoxide (DER 661) was first melted and mixed with CTBN at $160^{\circ} \mathrm{C}$. After degassing under vacuum for about 1.5 hours, the glass beads were dispersed in the CTBN/epoxide mixture for 1.5 hours. Then, the curing agent, 4,4'-diaminodiphenylsulphone (DDS), was mixed under the same vacuum condition at $160^{\circ} \mathrm{C}$ for $40 \mathrm{~min}$. The fully degassed mixture was put into a vertically mounted mold in a convection oven and cured at $160^{\circ} \mathrm{C}$ for 15 hours and $20 \mathrm{~min}$, followed by post-curing at $200^{\circ} \mathrm{C}$ for 2 hours. The compositions of the composites are given in Table 1. It should be noted that the content of each component is changed based on phr (part per hundred of epoxide by weight), not volume fraction. The epoxy matrix of DER $661 /$ DDS will be designated "661."

\section{Characterization}

The same fracture toughness tests and microscopy techniques, which have been used in our previous

Table 1. Formulations of Various Toughened Epoxies.

\begin{tabular}{ll}
\hline \multicolumn{1}{c}{ Component } & Composition (phr) \\
\hline Epoxide (DER 661) & 100 \\
$4,4^{\prime}$-Diaminodiphenylsulphone (DDS) & 12.2 \\
CTBN particles (Hycar $\left.1300 \times 13^{8}\right)$ & $0,1,2,3,4,5.5,7$ \\
Glass beads $^{2}$ & $0,4.8(2$ vol\%), \\
& $12.3(5$ vol\%), \\
& $26(10 \mathrm{vol} \%)$, \\
& $58.5(20 \mathrm{vol} \%)$, \\
& $100.3(30 \mathrm{vol} \%)$ \\
\hline
\end{tabular}

${ }^{1} \mathrm{phr}=$ Parts per hundred of resin by weight.

2Weight of only glass beads except rubber layers. 
studies on glass bead filled epoxies (23-25), were used. Since all the experimental details can be found elsewhere (23-25), only concise descriptions will be given here.

The critical stress intensity factor $\left(\mathrm{K}_{\mathrm{IC}}\right)$ was measured by loading single-edge-notched (SEN) specimens in three-point bend (3PB) geometry using a screw-driven Instron machine (Instron 4502). Specimens, 6.35 (thickness, B) $\times 12.7$ (width, W) mm, were notched by tapping a hammer on a razor blade inserted into them. The razor blades had been cooled in liquid nitrogen before inserted into specimens. $\mathrm{K}_{\mathrm{IC}}$ values were calculated from the load at failure (P) measured at a displacement rate of $2.54 \mathrm{~mm} / \mathrm{min}$ and a span (S) of $50.8 \mathrm{~mm}$ (35).

$$
K_{I C}=Y \frac{3 P S \sqrt{a}}{2 B W^{2}}
$$

$$
\begin{array}{r}
Y=1.93 \cdots 3.07(a / W)+14.53(a / W)^{2}- \\
25.11(a / W)^{3}-25.80(a / W)^{4}
\end{array}
$$

where $\mathrm{Y}$ is a shape factor and $\mathrm{a}$ is the crack length. Critical strain energy release rates $\left(G_{I C}\right)$ were calculated from $\mathrm{K}_{\mathrm{IC}}$ and modulus $(\mathrm{E})$ values using the following relationship $(35,36)$ :

$$
G_{I C}=\frac{K_{I C}^{2}}{E}
$$

To measure modulus values, uniaxial tensile tests were performed using small specimens (gauge section $=15 \times 5 \times 7 \mathrm{~mm}$ ) at loading rate $=2.54 \mathrm{~mm} / \mathrm{min}$.

Double-edge-notched four-point bend (DEN-4PB) technique (23-25) was used to examine sub-critically loaded cracks. Two almost identical cracks were prepared on an edge of the specimen. As the two cracks experienced loading in the four-point bend geometry, one of them would break and the other would just experience sub-critical loading. The resulting sub-critically loaded crack was observed by OM using the petrographic thin-sectioning technique (23-25).

Scanning electron microscopy (SEM) investigation was performed using a Hitachi $5-800$ on the fracture surface produced from SEN-3PB and DEN-4PB tests. Back-scattered electron SEM (B-SEM) was also performed, following the method of Hobb and Watkins (37). Samples were first carefully polished following the petrographic thin-sectioning method $(20,38)$ and stained in $1 \%$ aqueous $\mathrm{OsO}_{4}$ solution for 4 hours.

\section{RESULTS AND DISCUSSION}

The glass transition temperature $\left(T_{g}\right)$ of epoxy matrix was measured to check its dependence on composition which would give some indication of the amount of solutes in each phase, using a differential scanning calorimeter (DSC, Perkin Elmer DSC-7). Scanning rate was $10^{\circ} \mathrm{C} / \mathrm{min}$ and ca. $7 \mathrm{mg}$ of sample was used. As CTBN content increased from 0 to $7 \mathrm{phr}$. $\mathrm{T}_{\mathrm{g}}$ decreased from about $127^{\circ} \mathrm{C}$ to $117^{\circ} \mathrm{C}$. This $\mathrm{T}_{\mathrm{g}}$ drop can be attributed to a certain degree of miscibility between epoxy and CTBN. To understand this partial miscibility, not only thermodynamic terms but also kinetic terms need to be considered (23-25), because the phase separation of initially dissolved CTBN occurs during matrix curing. On the other hand, it was found that the existence of glass beads and CDI interlayers was not a factor in determining epoxy $T_{g}$ (23-25). Thus, the hybridization of tougheners does not make any significant differences in the miscibility of components or the cross-linked network structure of epoxy.

\section{Mechanical Properties of Composites}

Among various mechanical properties, the fracture toughness is the primary interest of this study. Figure 1 shows that the epoxy matrix can be successfully toughened by both tougheners: CTBN particles and glass beads. Changes in the fracture toughness of two types of hybrid composites with the increase of CTBN content can also be found. In this case, the volume fraction of each component varies, but the content ratio between glass beads and epoxy matrix does not (Table 1). As the CTBN content increases, the fracture toughness generally increases in all systems. However, in the two hybrid composite systems, the fracture toughness increases only up to about $2.6 \mathrm{MPam}^{1 / 2}$ by adding CTBN up to $4 \mathrm{phr}$, and does not significantly increase with subsequent addition of CTBN. On the other hand, the fracture toughness of CTBN/661 continues to increase with CTBN content in the composition range of Fig. 1.

A possible explanation for this result is as follows. Since matrix shear yielding was found to be an important source of toughness for both glass bead and rubber toughened systems $(3,20,21,23-25)$, it must be

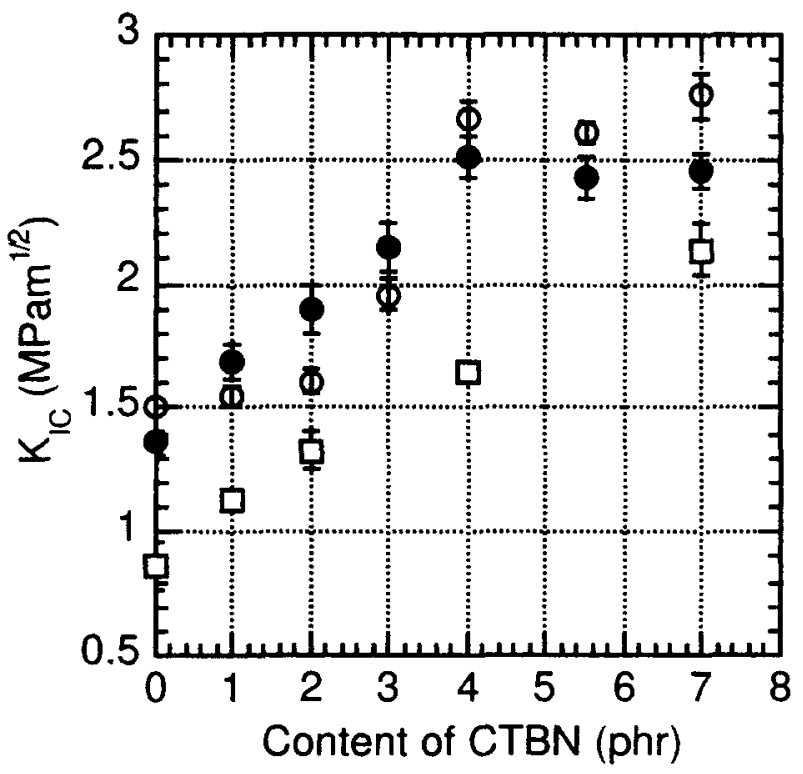

Fig. 1. Critical stress intensity factor versus CTBN content for hybrid-particulate composites: $\square$ CTBN/661, $026 \mathrm{phr}$ $L G / C T B N / 661$, 26 phr 0.5-LG/CTBN/661. 
important for hybrid-particulate composites as well. As the content of tougheners increases, the volume of matrix available for energy dissipation through shear yielding will eventually decrease. Consequently, fracture toughness data show a maximum with increasing toughener content, as can be seen in Fig. 1. When the same amount of CTBN is added, CTBN/661 has a larger volume fraction of matrix than the other two hybrid systems. Thus, the plateau could be detected only in the two hybrid systems of Fig. 1 .

Below 4 phr CTBN content, the 0.5-LG/CTBN/661 system shows the same toughening effect of CTBN as CTBN/661: The slope of fracture toughness versus CTBN content is almost the same in both systems. On the other hand, the LG/CTBN/661 system shows different trends with increasing CTBN content: Up to 2 phr, the addition of CTBN has no significant effect on fracture toughness, but from $2 \mathrm{phr}$ to $4 \mathrm{phr}$, it increases the fracture toughness of composites up to 2.6 $\mathrm{MPam}^{1 / 2}$. In the following section on microscopy studies, the effect of CTBN content will be discussed in detail. Above 4 phr CTBN, non-encapsulated systems have higher fracture toughness than encapsulated systems. When a relatively large amount of tougheners is used, understanding the fracture behavior of hybrid-particulate composites becomes more difficult, because of possible significant interactions between tougheners. Thus, understanding the results below 4 phr will first be attempted in the current research.

The error range in Fig. 1 is the standard deviation of more than 12 measured values. This number of tests is large enough to make the differences discussed above significant with respect to the error. For 2 and 4 phr CTBN cases, the number of tests was increased to 18 to check the reproducibility of data.

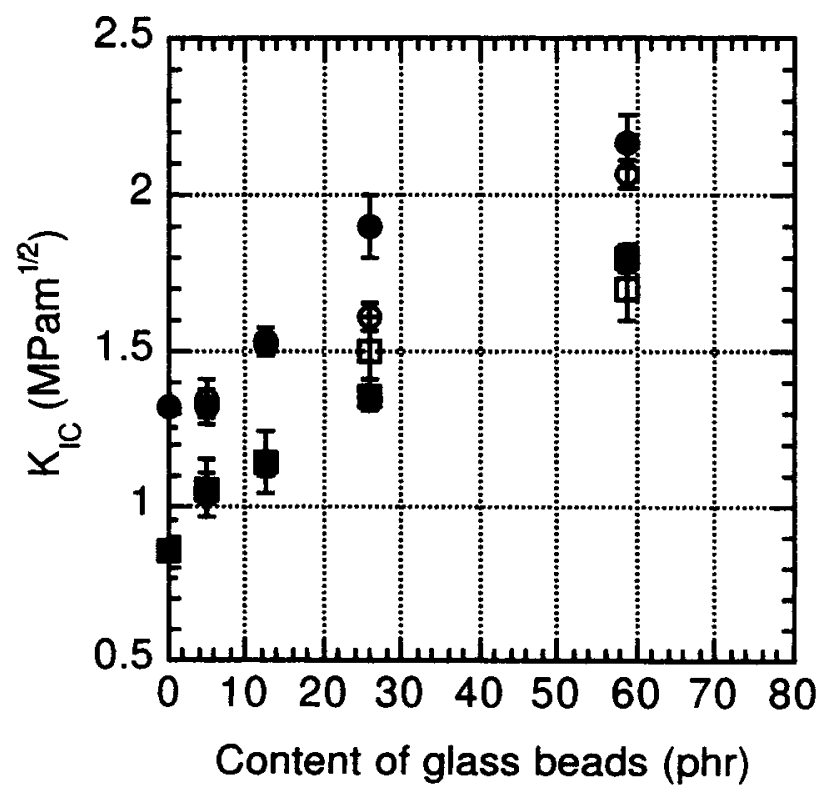

Fig. 2. Critical stress intensity factor versus glass bead content for hybrid-particulate composites: $\square L G / 661,0 \mathrm{LG} / 2 \mathrm{phr}$ CTBN/661, 0.5-LG/661, 0.5-LG/2 phr CTBN/661.
Figure 2 shows the typical fracture toughness data obtained by changing glass bead content and keeping CTBN content constant at $2 \mathrm{phr}$. (When CTBN content is constant at $3 \mathrm{phr}$, the same trends as Fig. 2 shows were obtained.) In Fig. 2, obviously, fracture toughness $\left(\mathrm{K}_{\mathrm{IC}}\right)$ increases with glass bead content. Unlike in Fig. 1, the rubber encapsulation does not produce significant differences except at 26 phr glass bead content. The reason for this might be found in references 23-25 where only $26 \mathrm{phr}$ glass bead filled systems (without CTBN particles) have a difference in debonding zone size caused by the rubber encapsulation around glass beads ( 26 and $58.5 \mathrm{phr}$ correspond to 10 and $20 \mathrm{vol} \%$ in references $23-25$, respectively). Consequently, the differences between encapsulated and non-encapsulated systems found in Fig. 1 is observable only in a certain composition range. One more finding in Figs. 1 and 2 is that the fracture toughness of epoxies increases more when CTBN is added than when the same amount of glass beads is used. This confirms that CTBN is a more effective toughener than glass beads.

By using $E q 2, \mathrm{G}_{\mathrm{IC}}$ values are calculated and given in Fig. 3, which basically shows the same details as Fig. 1. This likely indicates that the moduli of these composites are not significantly affected by the rubber encapsulation or the variation of CTBN content, because Eq 2 uses $\mathrm{K}_{\mathrm{IC}}$ and modulus data to calculate $\mathrm{G}_{\mathrm{IC}}$ (39). The modulus data in Fig. 4 is consistent with such an interpretation. Although CTBN content increases up to $7 \mathrm{phr}$, the moduli of the composites do not significantly decrease. Moreover, there is no difference between the moduli of encapsulated and non-encapsulated systems. The only stiffening effect of adding glass beads into epoxies is obvious. If more

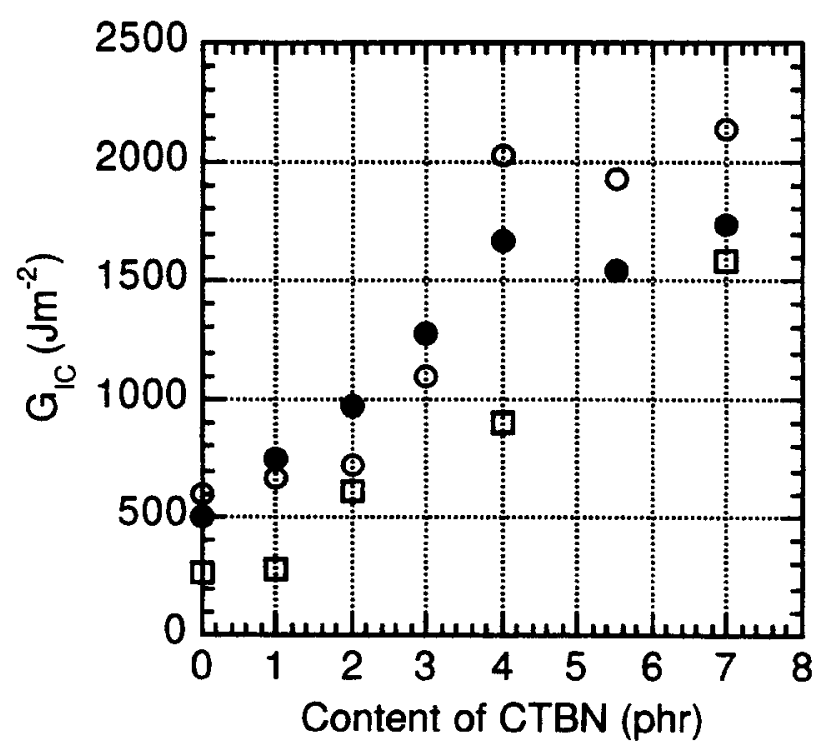

Fig. 3. Critical strain energy release rate versus CTBN content for hybrid-particulate composites: $\square$ CTBN/661. 026 phr LG/CTBN/661, 26 phr 0.5-LG/CTBN/661. 


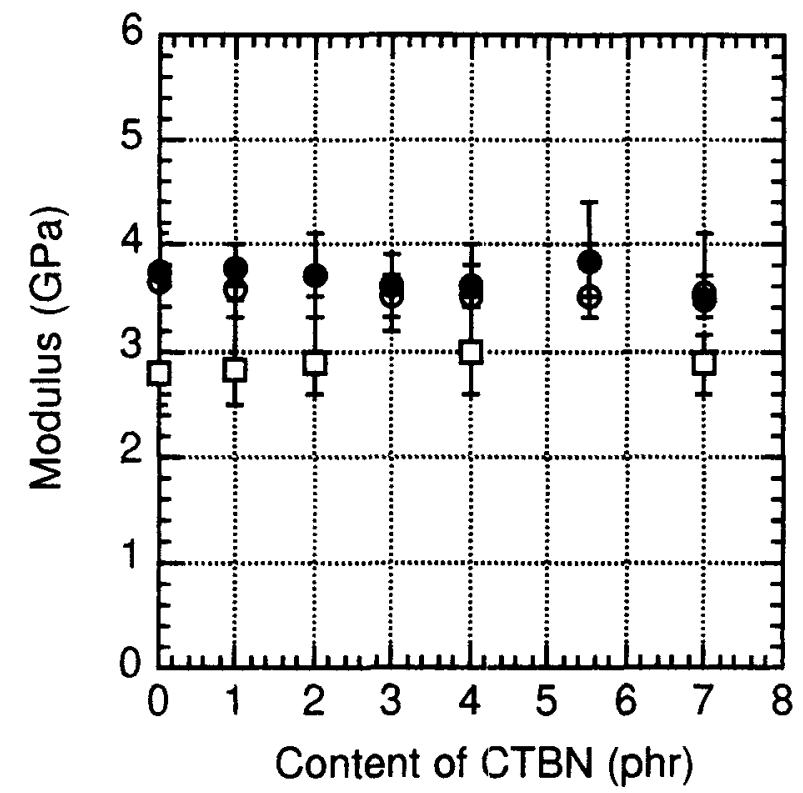

Fig. 4. Tensile modulus versus CTBN content for hybrid-particulate composites: $\square$ CTBN/661, O 26phr LG/CTBN/661, 26 phr $0.5-L G / C T B N / 661$.

than 7 phr CTBN is added, the modulus is expected to eventually drop. In the current experiment, the CTBN content is limited to 7 phr, because we are not interested in cases where the moduli may be significantly compromised.

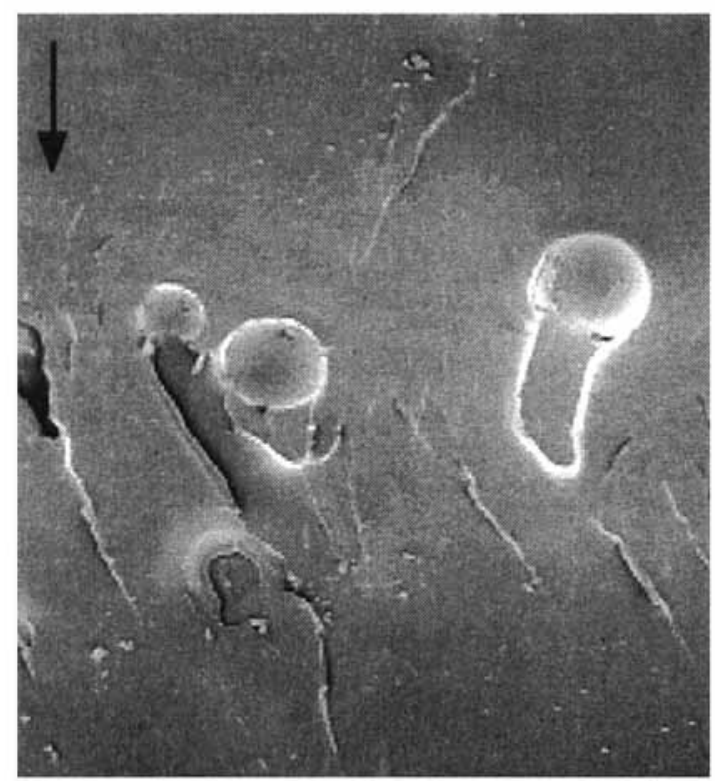

(A)

$60 \mu \mathrm{m}$

\section{Microscopy Study I-SEM Micrographs}

Figure 5 shows the fracture surface of composites containing 2 phr CTBN. Glass beads and step structures are visible in these micrographs. Clear evidence of debonding of glass beads can be found in the encapsulated system $((B))$, but not in the non-encapsulated system ((A)). On the fracture surface of the nonencapsulated system, partially debonded or even fully debonded glass beads were found, but much less commonly compared to the case of the encapsulated system.

Another difference between encapsulated and nonencapsulated systems can be noticed in the micrographs of the matrix region in Fig. 6. While CTBN cavities (17-22) are almost invisible in the micrograph (A) of the non-encapsulated system, they can be easily found in the micrograph $(B)$ of the encapsulated system. By measuring the diameters of more than 200 cavities, their average diameter $\left(D^{m}\right)$ was obtained and given in the caption of Fig. 6. The encapsulated system has around three times larger cavities than the non-encapsulated system. If the initial sizes of CTBN particles before loading are the same in both systems, the larger cavities must result from more plastic dilatation of matrix (cavity growth) which requires more energy. In fact, the fracture toughness of the encapsulated system is larger than that of the non-encapsulated system (Fig. 1 or 3 ). The cavity sizes in the hybrid composites are also compared with that in a simple binary blend, CTBN/661 of the micrograph (C), having the same epoxy-to-CTBN composition

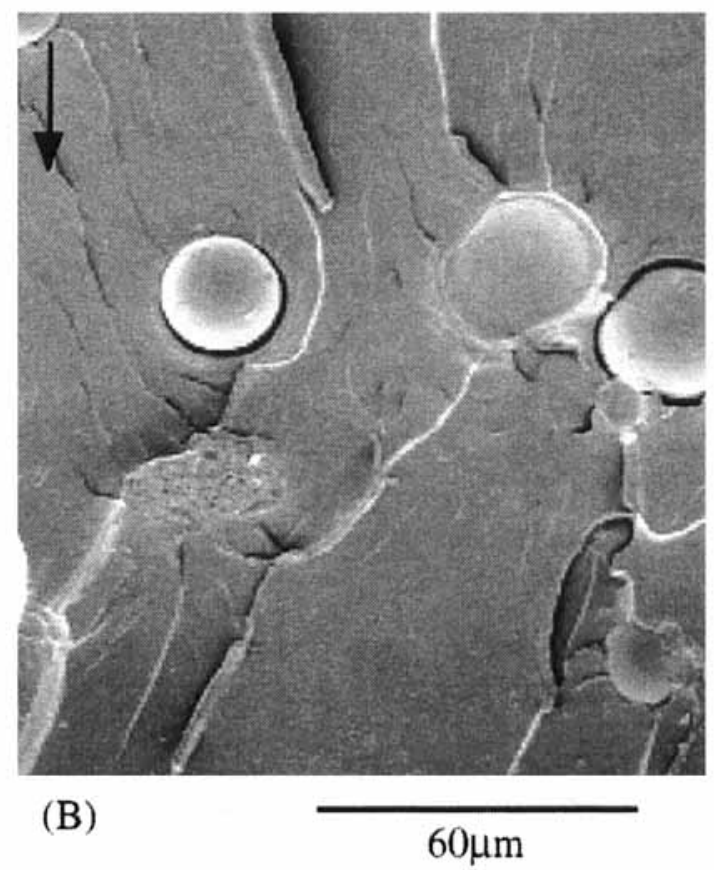

Fig. 5. SEM micrographs of the fracture surface of SEN-3PB specimens (process zone): (A) $26 \mathrm{phr} L \mathrm{LG} / 2 \mathrm{phr}$ CTBN/661; (B) $26 \mathrm{phr}$ $0.5-L G / 2$ phr CTBN/661. The arrows indicate the direction of crack propagation. 


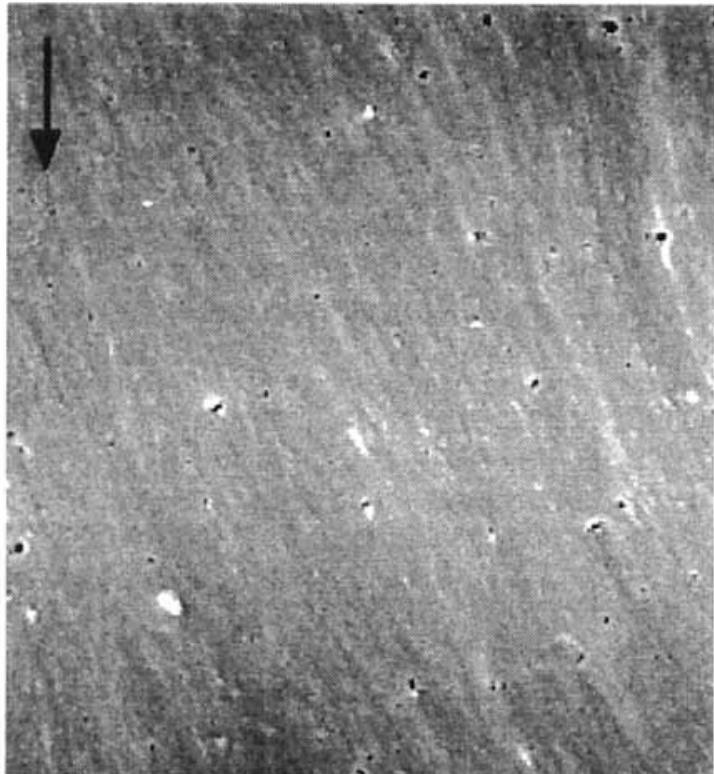

(A)

$3 \mu \mathrm{m}$

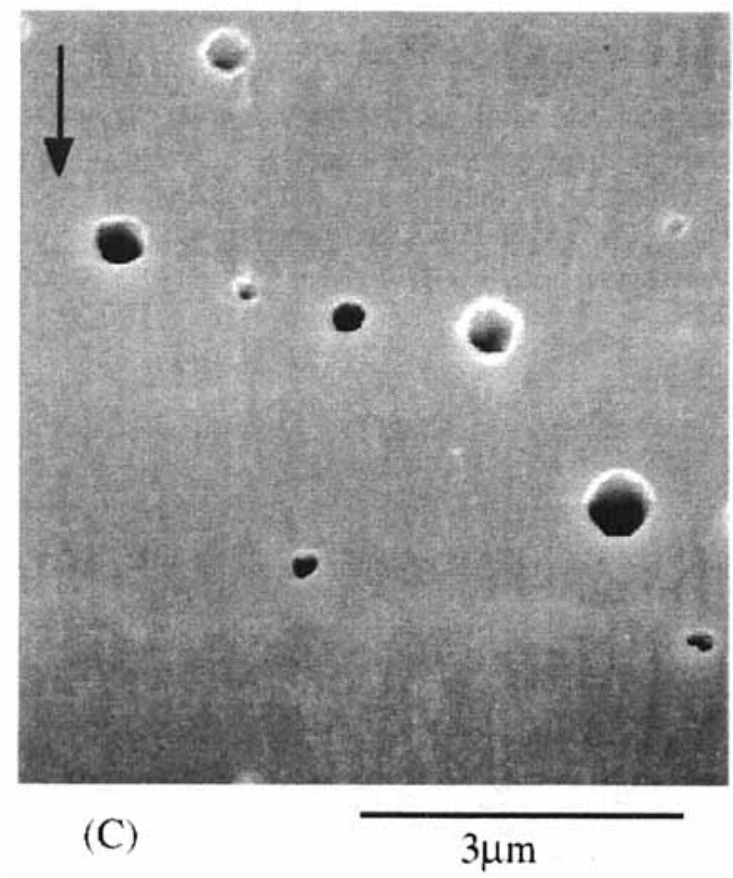

ratio as the hybrid composites. The cavity size of the simple binary blend is considerably larger than that of the non-encapsulated system, and slightly larger than that of the encapsulated system.

The differences found between the non-encapsulated and the encapsulated systems disappear with increase in CTBN content. Figure 7 shows the fracture surface of composites toughened with 4 phr CTBN. Since no significant difference was found in the low magnification views of encapsulated and non-encapsulated systems,

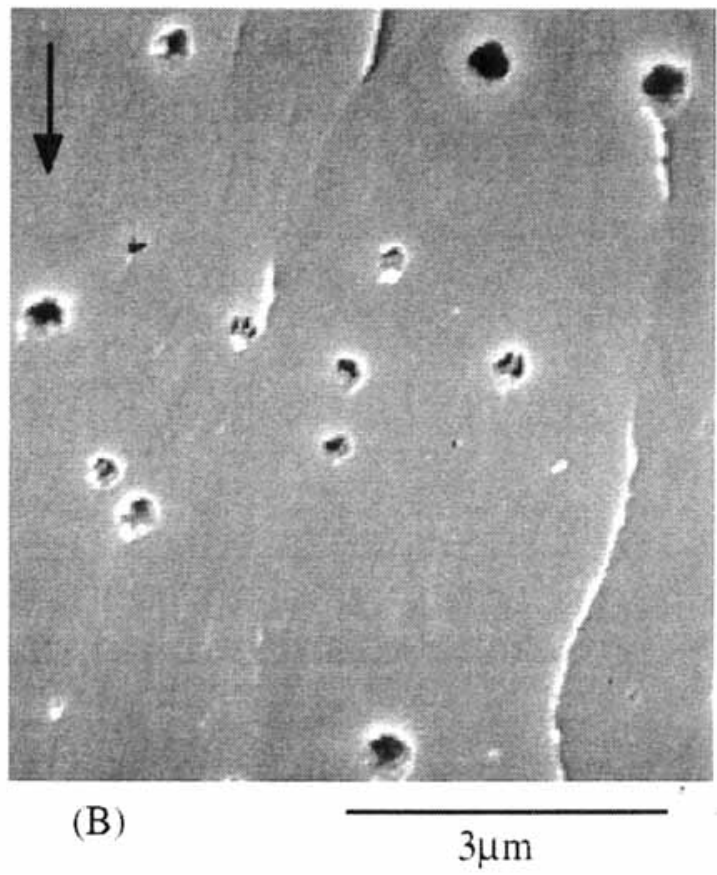

Fig. 6. SEM micrographs of the fracture surface of SEN-3PB specimens (process zone): (A) 26 phr LG/2 phr CTBN/661 (average cavity diameter $\left(D^{m}{ }_{c}\right)=0.13 \mu \mathrm{m}$ ); (B) $26 \mathrm{phr}$ $0.5-L G / 2 \mathrm{phr} C T B N / 661\left(D^{\mathrm{m}}{ }_{c}=0.31 \mu \mathrm{m}\right)$; (C) $2 \mathrm{phr}$ $C T B N / 661\left(D^{m}{ }_{c}=0.41 \mu \mathrm{m}\right)$. The arrows indicate the direction of crack propagation. 


\section{Micro-Mechanical Deformation Mechanisms}

They result from the aggregation of several CTBN particles having matrix materials between them. This kind of structure has already been found in various toughened polymers (3).

The difference in cavity size due to rubber encapsulation exists only when glass bead and CTBN contents in hybrid-particulate composites are about 26 and 2 phr respectively. The difference: in fracture toughness due to the rubber encapsulation was also found in the same composition range. These results can be explained in three different ways:

1. If the two different types of glass beads, encapsulated and non-encapsulated, could produce different local stress fields, different cavity growth could result.

2. During the curing of epoxy resin, the surface of glass beads or the CDI adduct layers on it might
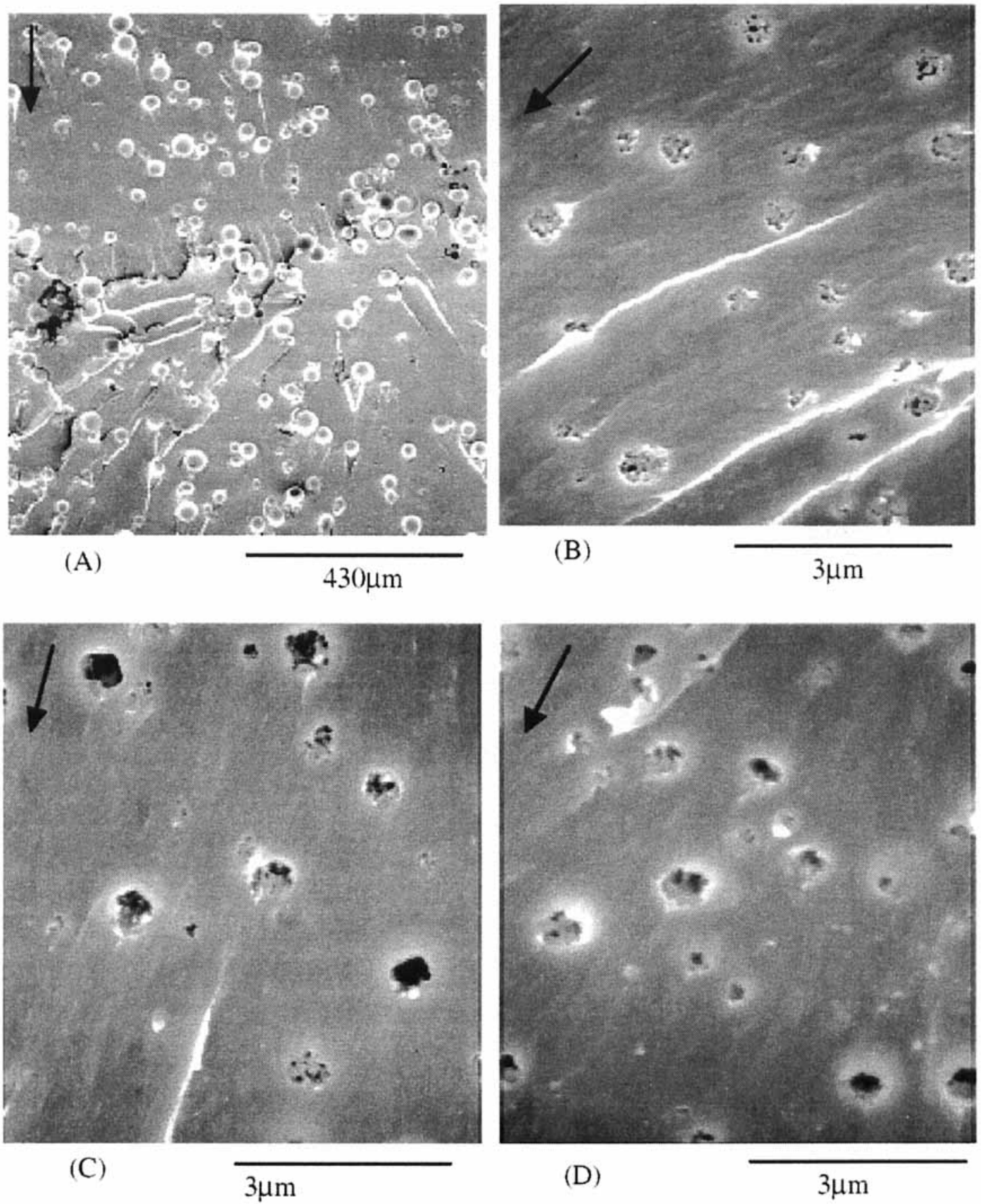

Fig. 7. SEM micrographs of the fracture surface of SEN-3PB specimens (process zone): $(A)$ and (B) $26 \mathrm{phr} L G / 4 \mathrm{phr} C T B N / 661\left(D^{m}{ }_{c}=\right.$ $0.45 \mu \mathrm{m}):(C) 26 \mathrm{phr} 0.5-\mathrm{LG} / 4 \mathrm{phr} C T B N / 661\left(D^{\mathrm{m}}{ }_{c}=0.50 \mu \mathrm{m}\right) ;(D) 4 \mathrm{phr} C T B N / 661\left(D^{\mathrm{m}}{ }_{c}=0.49 \mu \mathrm{m}\right)$. The arrows indicate the direction of crack propagation. 

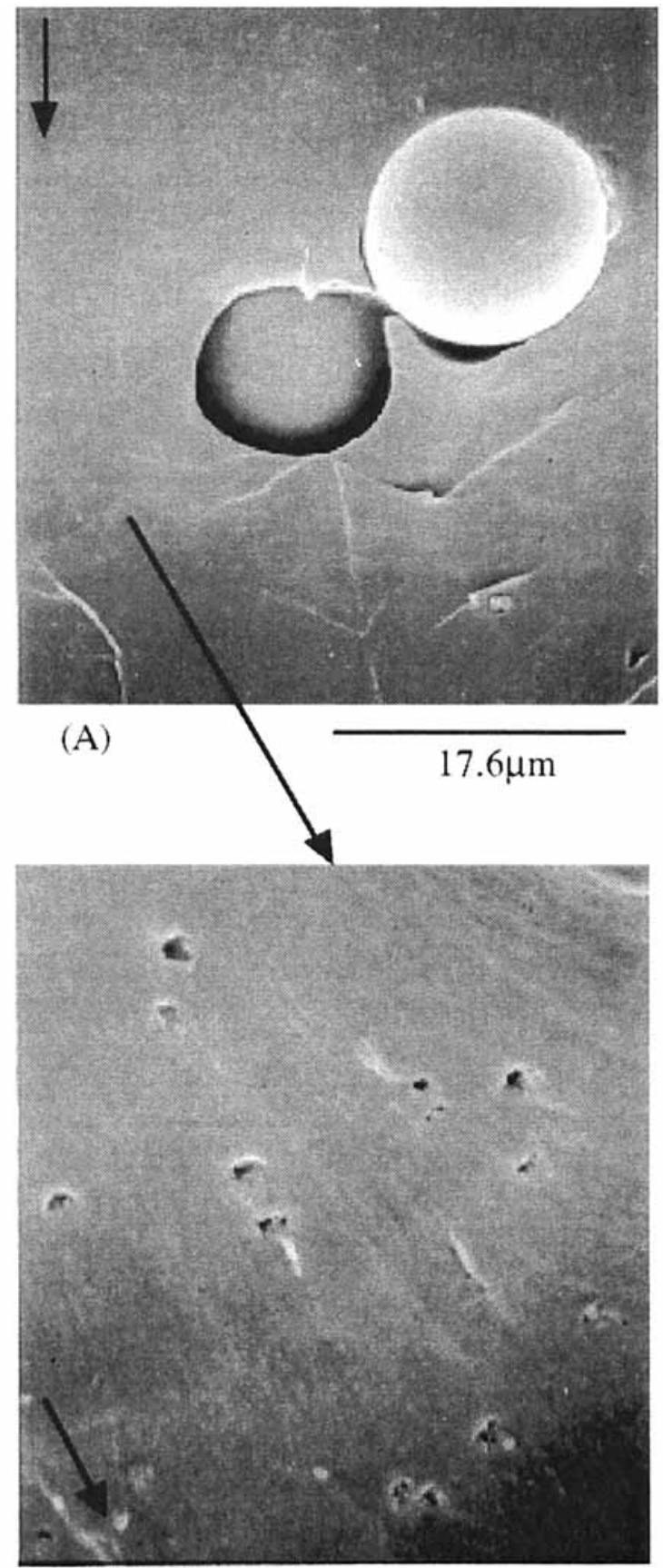

(C)

$$
3.0 \mu \mathrm{m}
$$

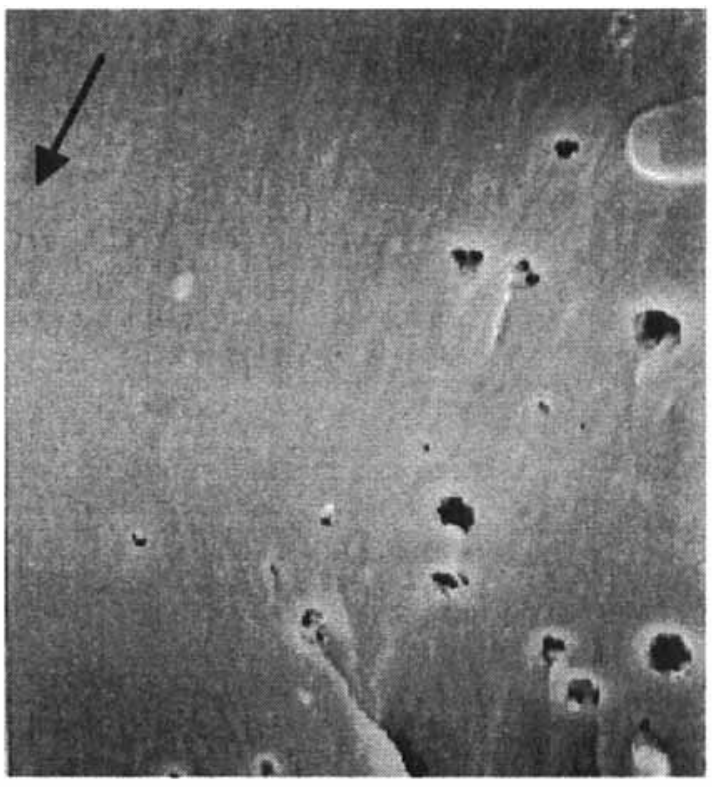

(B)

\section{$6.0 \mu \mathrm{m}$}

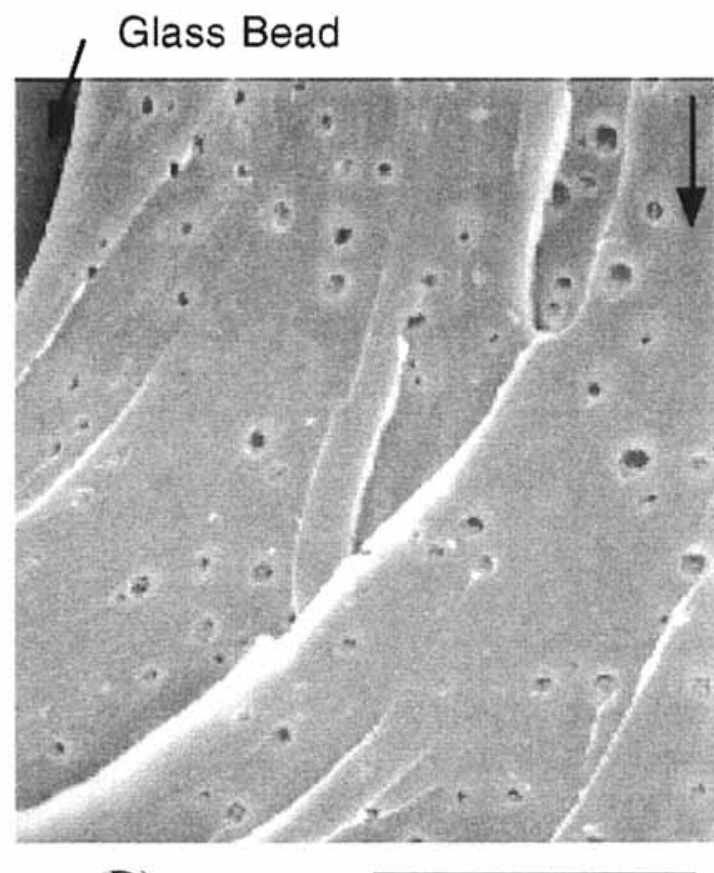

(D)

$$
3.0 \mu \mathrm{m}
$$

Fig. 8. SEM micrographs of the fracture surface of SEN-3PB specimens (process zone): (A) 4.8 phr LG/2phr CTBN/661; (B) far from glass beads in $4.8 \mathrm{phr}$ LG/2phr CTBN/661; (C) near glass beads in 4.8 phr LG/2 phr CTBN/661; (D) near glass beads in 26 phr LG/3 phr CTBN/661. The arrows indicate the direction of crack propagation.

influence the phase separation behavior of CTBN. The different cavity sizes could result from the different CTBN particle sizes before loading.

3. Differences in process zone size can cause differences in cavity growth. This is because the cavities in the process zone have grown while a crack front propagates stably around them. In other words, the growth of a cavity depends on loading and unloading rates, so slow stable crack propagation in a larger area around cavities will allow the cavities to grow to the greatest extent.

To check the first possible answer, cavity sizes near to and far from glass beads were carefully examined. 


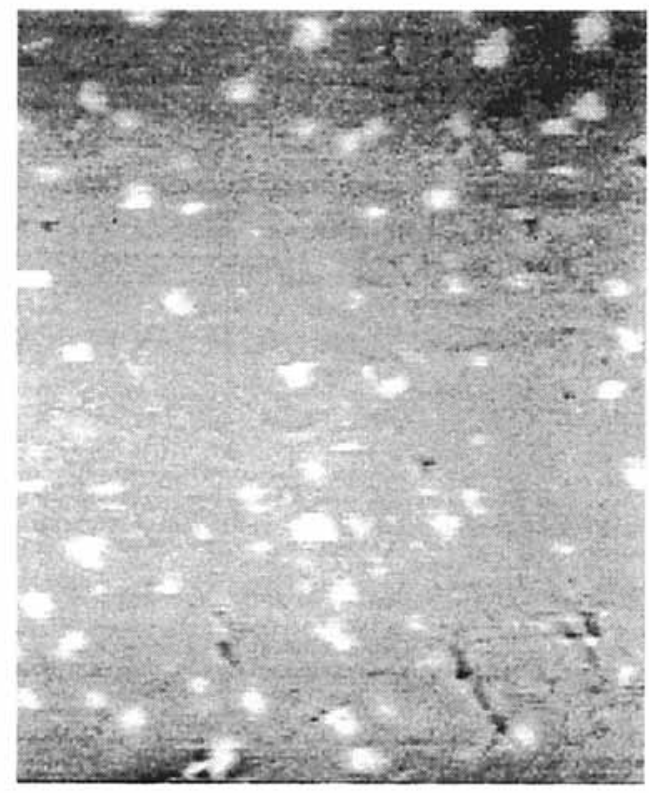

(A)

$6.0 \mu \mathrm{m}$

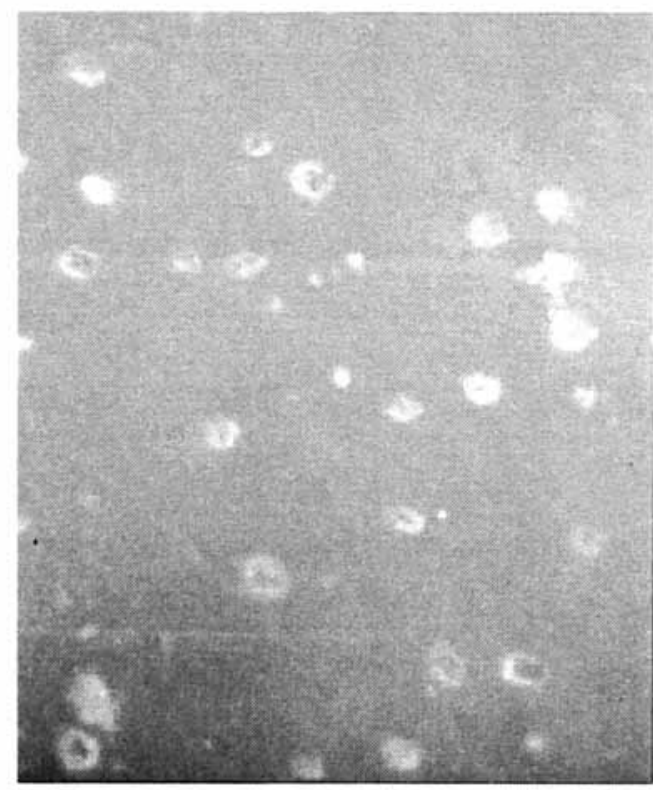

(C)

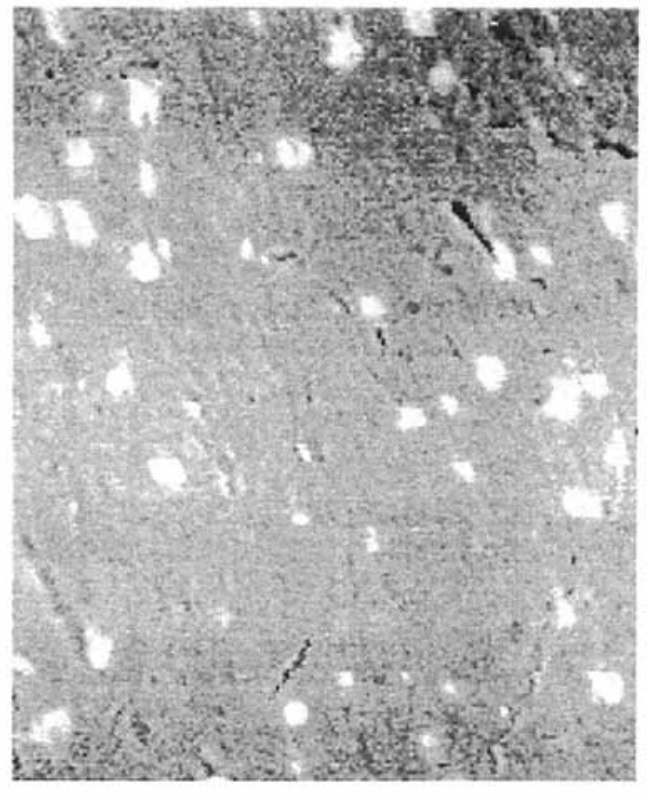

(B)

Fig. 9. Back-scattered electron SEM micrographs of polished surface: (A) 26 phr LG/4 phr CTBN/661: (B) 26 phr 0.5-LG/4 phr CTBN/661: (C) 4 phr CTBN/661.

Figures $8 A, B$, and $C$ are the SEM micrographs of 4.8 phr LG/2 phr CTBN/661. Since only $4.8 \mathrm{phr}$ glass beads are used in this composite, the volume fraction of glass is so low that there is almost no overlap among the local stress fields generated by glass beads, and the stress fields near and far from glass beads must be different. Thus, if different stress fields can induce significantly different cavity growth, there must be differences in cavity size according to the relative position of cavity to glass beads. The micrograph $C$ shows the fracture surface near the two glass beads in $A$, and the micrograph $B$ shows a different region in the same specimen but far from glass beads. No significant difference in cavity size actually exists between the two micrographs. This finding was confirmed by many observations on the fracture surface 
of more than six different specimens of encapsulated and non-encapsulated glass beads. Smaller cavities are sometimes found nearer glass beads than in the rest of matrix, as can be seen in Fig. 8D. The smaller cavities could result from the release of triaxial stress by the debonding of glass beads. However, the region containing the small cavities is too small to explain the different cavity sizes found in Fig. 6 .

The second possible explanation can be examined by observing CTBN particles in composites before loading by using a staining technique and SEM in the back-scattered electron mode (B-SEM) (37). $\mathrm{OsO}_{4}$ was used to stain the unsaturated bonds in CTBN. As can be seen in Fig. 9, no significant difference in the size of CTBN particles is found among the three composites containing $4 \mathrm{phr}$ CTBN (LG/CTBN/661, 0.5-LG/ CTBN/661, and CTBN/661). Although the clear images of CTBN particles in $2 \mathrm{phr}$ CTBN toughened systems were not successfully obtained by using B-SEM, there is no reason for the CDI adduct layers (or glass bead surface) to affect the phase separation behavior of CTBN in only the 2 phr CTBN toughened systems, but not in the $4 \mathrm{phr}$ systems. Since the CDI adduct has CTBN segments, it can be argued that CTBN initially dissolved in epoxides may migrate to the CDI layer, or promote the phase separation between CTBN and epoxy resin. However, if the layers really have these capabilities, the cavity size in encapsulated systems must be smaller than that in non-encapsulated systems. Evidently, this is not the case in the current results. The $\mathrm{T}_{g}$ data discussed above are also inconsistent with the second possible explanation: The existence of glass beads and interlayers was found not to significantly change the $T_{g}$ of the epoxy matrix. Thus, it appears unable to change the amount of CTBN dissolved in the matrix and also the amount of CTBN precipitated out.

Among the three possibilities, only the third is left unexamined. Later, the third possible explanation will be proposed as the correct answer.

\section{Microscopy Study II-OM Micrographs}

Figure 10 provides the OM micrographs of sub-surface damages in $26 \mathrm{phr}$ LG/2 phr CTBN/661. Around the sub-critically loaded crack tip in the micrograph (A), there are fine dark lines. Since these lines are connected to the crack tip, the crack tip appears to bifurcate into 4 to 6 microcracks. In reality, those lines were identified as micro-shear bands by the same experimental technique described in references 23-25. Except for the micro-shear bands, there is no other micro-mechanical deformation distinctly visible in $A$. The dark sphere in the middle of $A$ is just a defect introduced by polishing. Similar dark spheres can be found everywhere, around the crack tip as well as far from the crack tip. Discussions on these artifacts in polished thin-sections are given in reference 23.

In the micrographs $B$ and $C$, sub-surface damages in the process zone of a fractured SEN-3PB specimen

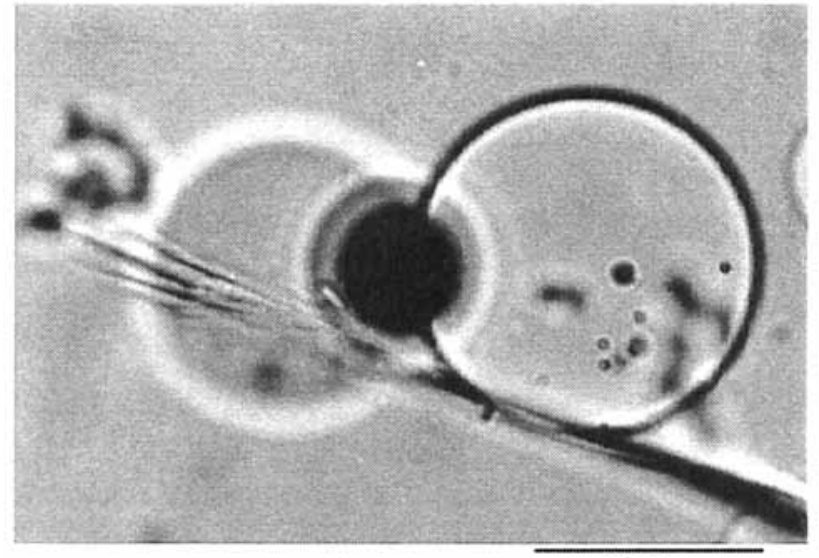

(A)

$31.3 \mu \mathrm{m}$
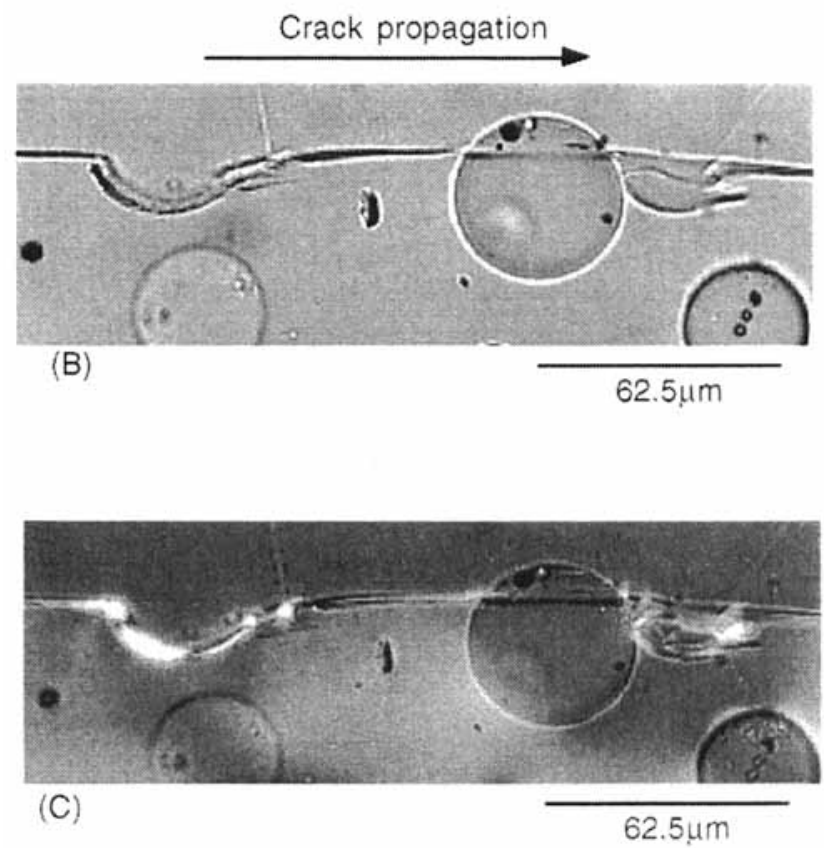

Fig. 10. Transmitted light optical micrographs of thin sections of $26 \mathrm{phr}$ LG/2 phr CTBN/661: (A) tip of sub-critically loaded crack in a DEN-4PB specimen; (B) process zone in a SEN-3PB specimen (without polarizers); (C) the same region as that in (B), but between crossed polarizers.

can be identified. First of all, conclusive evidence of diffuse shear yielding around the fracture surface of the epoxy matrix facing debonded glass beads (debonded matrix) is clearly obtained. Figure $10 \mathrm{C}$ shows a birefringent shear yielded region around the debonded matrix. The other weak birefringence around glass beads in this micrograph is caused by thermal residual misfit between glass beads and the matrix. In the micrograph $B$, micro-shear bands can also be discerned around the debonded matrix.

Although the composite in Fig. 10 contains $2 \mathrm{phr}$ CTBN, what the OM micrographs show is the same as 

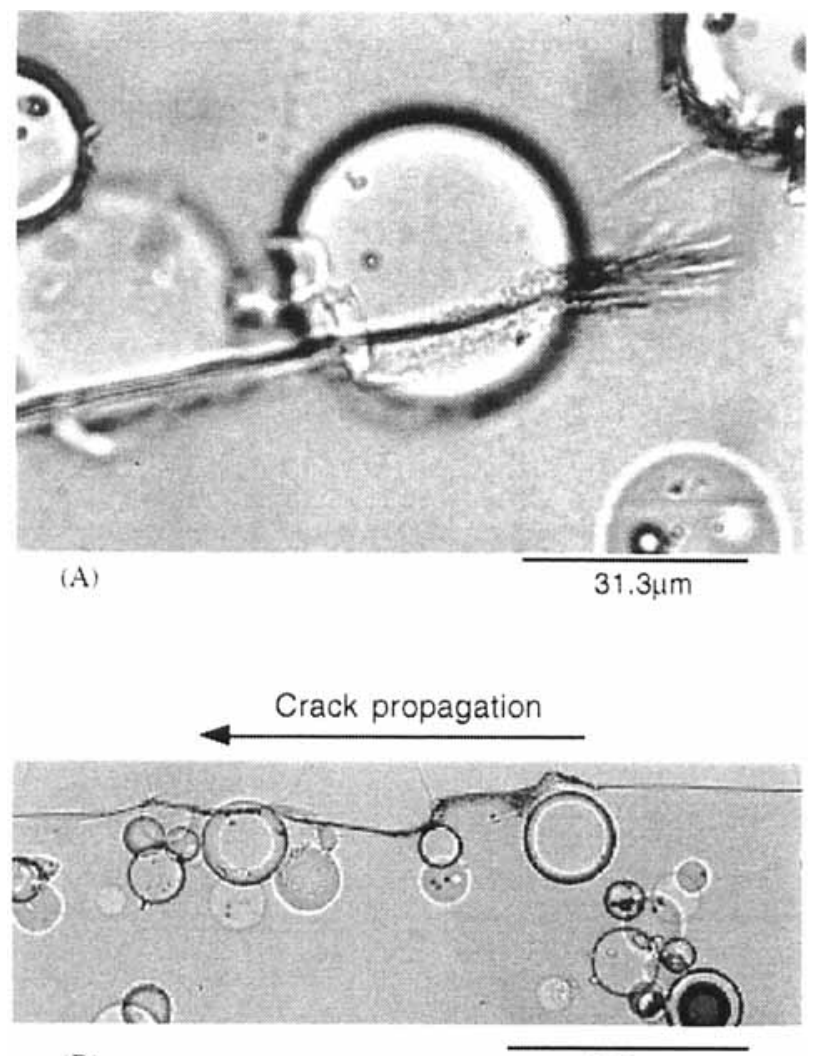

(B)

$125 \mu \mathrm{m}$

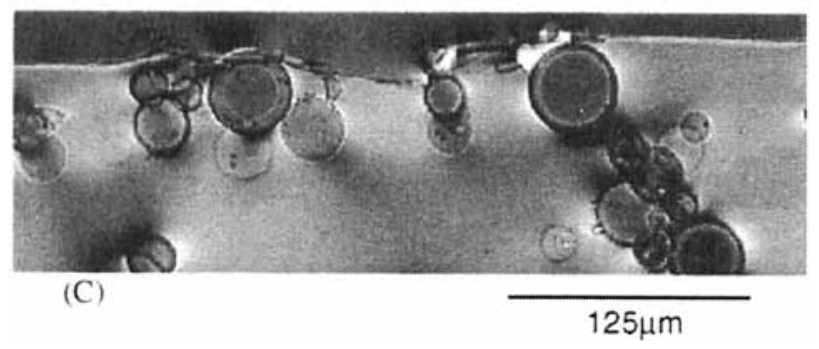

Fig. 11. Transmitted light optical micrographs of thin sections of 26 phr 0.5-LG/2 phr CTBN/661: (A) tip of sub-critically loaded crack in a DEN-4PB specimen: (B) process zone in a $S E N-3 P B$ specimen (without polarizers): (C) the same region as that in (B), but between crossed polarizers.

what the OM micrographs of LGi/661 show (23-25). By contrast. the OM micrographs of $26 \mathrm{phr} 0.5-\mathrm{LG} / 2$ phr CTBN/661 in Fig. 11 show different micro-mechanical deformations related with the existence of CTBN particles. Although CTBN content is still $2 \mathrm{phr}$, CTBN cavities and matrix shear bands initiated by the cavitation are visible in this encapsulated system: In Fig. $11 \mathrm{~A}$ of a sub-critically loaded crack, there are small dark cavities and fine shear bands. They are the same typical micro-mechanical deformations found in CTBN/661 binary blends (23-25).

The OM micrographs of a fractured SEN-3PB specimen, $B$ and $C$, show the same micro-mechanical deformations as found in $A$. Shear bands are much finer here than in Fig. 10, and the process zone here seems to be larger than that in Fig. 10. Since CTBN cavities coexist with shear bands, the cavitation/ shear yielding zone in $B$ and $C$ appears dark. In the process zone of Fig. $11 \mathrm{C}$, birefringent diffuse shear yielded regions are also visible, which seem to be related with step formation. However, the diffuse shear yielded regions around steps were not generally observed in our $O M$ investigation. In fact, the steps in Fig. $11 B$ and $C$ are significantly larger than the steps normally found on the fracture surface of the same composite (Fig. 5).

In hybrid-particulate composites, as the content of a toughener increases, the micro-mechanical deformations triggered by the toughener will occur more noticeably. Likewise, as more and more CTBN is added into $10 \mathrm{vol} \%$ glass bead filled epoxies, the cavitation/shear yielding of CTBN particles (17-22) will replace the micro-shear banding as the major deformation mechanism. The micro-shear banding was shown to be the major energy dissipating mechanism for glass bead filled epoxies in our previous studies (23-25). In encapsulated systems, this transition of the major deformation mechanism seems to occur at lower CTBN contents than in non-encapsulated systems. Although CTBN content is 2 phr in both encapsulated and non-encapsulated systems (Figs. 10 and 11), cavitation/shear yielding is more noticeable in the encapsulated system. As a result, Figs. 10 and 11 support what was found in Figs. 5 and 6 .

Figure 12 shows the typical OM micrographs of 26 phr LG/4 phr CTBN/661. Basically, the OM micrographs of encapsulated systems containing $4 \mathrm{phr}$ CTBN (26 phr 0.5-LG/4 phr CTBN/661) were not found to be different from the micrographs of non-encapsulated systems in Fig. 12. Similar to the SEM studies, the difference found in $2 \mathrm{phr}$ CTBN cases was not found in the OM micrographs of $4 \mathrm{phr}$ systems. In Fig. $12 A$ and $B$, well-developed cavities and shear bands form dark regions. Interestingly, this region is developed between glass beads. The existence of glass beads seems to enhance this cavitation/shear yielding mechanism. In fact, when the CTBN content (phr) is the same, the size of cavitation/shear yielding zone was found to be larger in hybrid-particulate composites than in CTBN/661 binary blends. Several dark cavitation/shear yielding regions isolated from the main crack tip can be found around glass beads in $A$ and $B$. Since the glass beads do not seem to be debonded from matrix, this finding leads us to surmise that the cavitation of CTBN particles may precede the debonding of glass beads.

The cavitation/shear yielding mechanism can be enhanced by the local stress concentration generated by the existence of glass beads. From this standpoint, the hybridization of glass beads and CTBN particles seems to be synergistic. However, as the cavitation/ shear yielding mechanism is more enhanced by glass beads, the micro-shear banding triggered by glass 

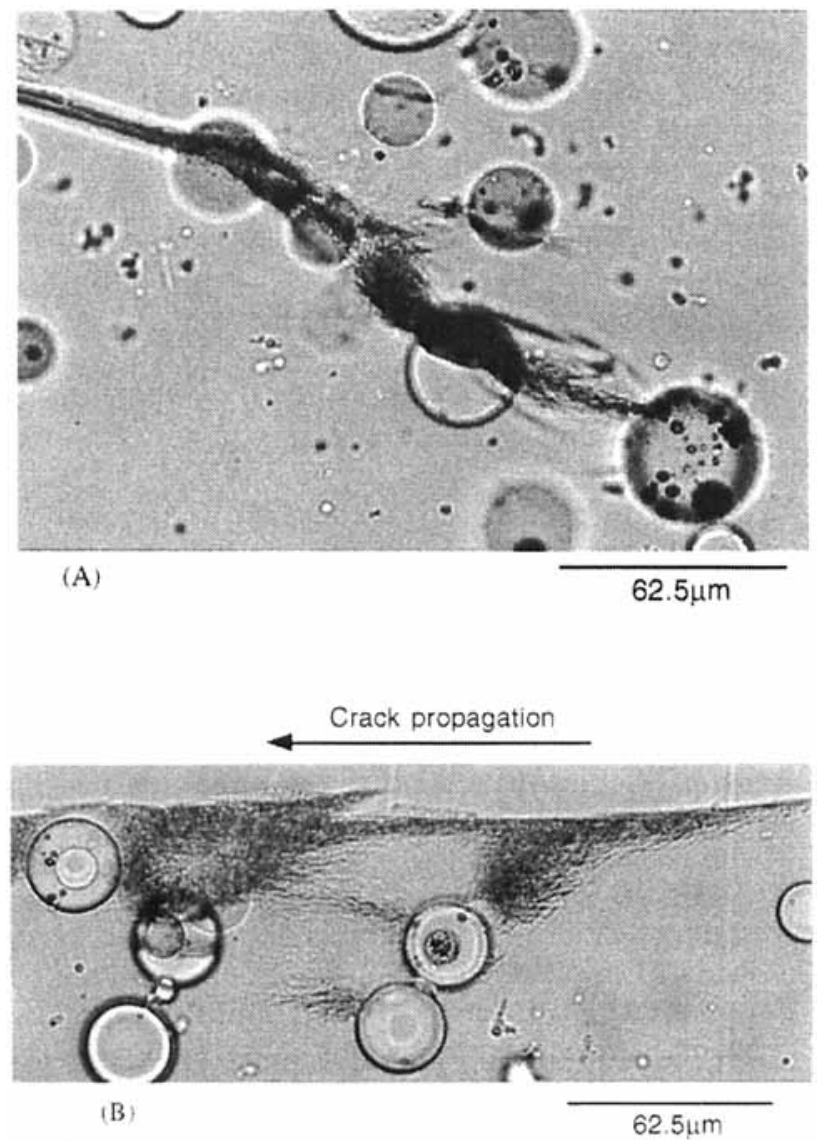

Fig. 12. Transmitted light optical micrographs of thin sections of $26 \mathrm{phr}$ LG/4 phr CTBN/661: (A) tip of a sub-critically loaded crack in a $D E N-4 P B$ specimen; $(B)$ process zone in a SEN-3PB specimen.

beads seems to occur less frequently (Figs. 10-12). The same micro-shear bands found in glass bead filled epoxies cannot be discerned in the micrographs of hybrid-particulate composites containing more than 2 phr CTBN. Even at higher magnification, the dark regions in Figs. $12 A$ and $B$ do not show characteristic features of micro-shear bands. Consequently, as the CTBN content increases in 10 vol\% glass bead filled epoxies, the role of glass beads seems to be changed from initiating micro-shear banding to enhancing cavitation/shear yielding. This may explain the results of the toughening effect in Fig. 1, which exhibit little synergism.

From the above results, it is possible to predict a series of events occurring in the fracture of the hybrid systems. As intact materials ahead of crack tip experience more and more loading, the cavitation of CTBN particles first occurs, and the debonding of glass beads and matrix shear yielding follows. Finally, the crack front moves into the materials.

\section{Analysis of Process Zone Size}

Process zone size was measured from the SEM and OM micrographs (at least 15 measurements using

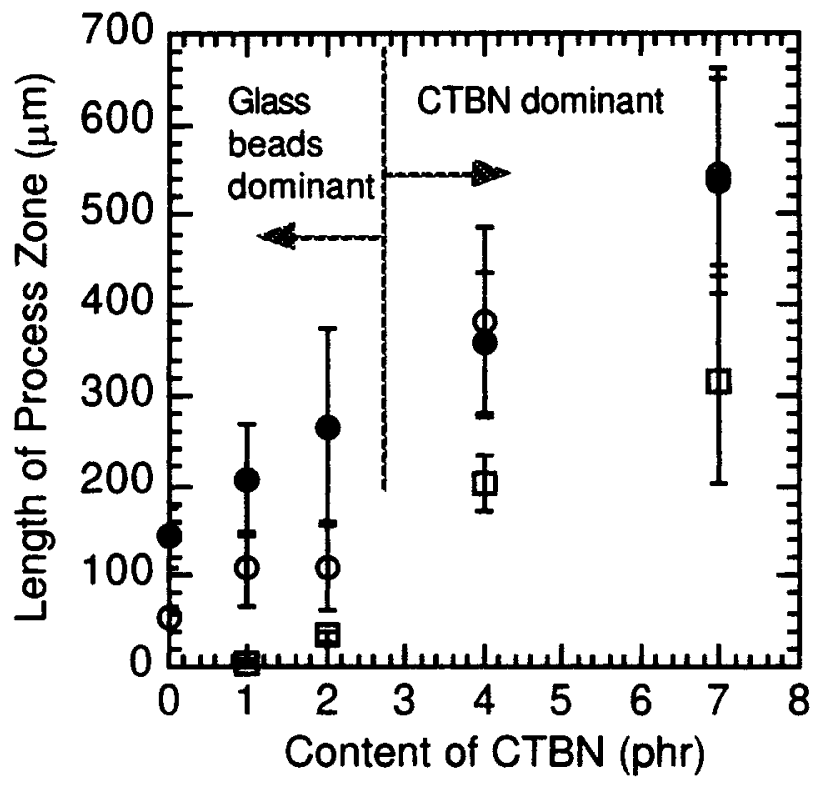

Fig. 13. Size of process zone in SEN-3PB specimens of hybridparticulate composites measured by OM and SEM on fracture surface: $\square$ CTBN/661, O $26 \mathrm{phr} L \mathrm{LG} / \mathrm{CTBN} / 661,026 \mathrm{phr}$ $0.5-L G / C T B N / 661$.

more than three specimens). Phenomenologically, the process zone was treated as the region containing debonded glass beads and larger CTBN cavities than those in fast-fracture regions. In the microscopy studies, it was found that the three regions, viz., debonding zone, cavitation zone and shear yielding zone, had almost the same location and size in a composite. Consequently, differentiating the process zone into the three micro-mechanical deformation zones was not attempted.

Figure 13 shows the process zone sizes of the composites whose fracture toughness values were plotted in Fig. 1. Below $4 \mathrm{phr}$ CTBN, the process zone size is higher in encapsulated systems than in non-encapsulated systems. Interestingly, fracture toughness was found to be also higher in encapsulated systems than in non-encapsulated systems (Fig. I). If the process zone size of the hybrid-particulate composites $\left(2 r_{h}\right)$ follows the simple additive rule having no additional terms for the interactions between tougheners, it can be calculated from the process zone size of glass bead filled epoxy $\left(2 r_{g}\right)$ and that of CTBN toughened epoxy $\left(2 r_{c}\right): 2 r_{h}=2 r_{g}\left(f_{g}\right)+2 r_{c}\left(f_{c}\right)$, where $f_{g}$ and $f_{c}$ are the volume fractions of glass bead and CTBN, respectively. In Fig. 13, the $2 r_{g}$ values of all encapsulated and nonencapsulated systems may be approximately 50 and $140 \mu \mathrm{m}$, respectively. It seems to be the case in Fig. 13 that, while the process zone size of encapsulated systems nearly follows this simple rule, those of nonencapsulated systems do not. As CTBN content increases in LG/CTBN/661, the process zone size increases almost linearly below 2 and above $4 \mathrm{phr}$ CTBN, but between 2 and 4 phr CTBN, the size increases more rapidly with CTBN content. This might 
explain why the fracture toughness of encapsulated systems is higher than that of non-encapsulated systems below $4 \mathrm{phr}$ as found in Fig. 1. This will be the third possible explanation given in the previous section.

It was found in our previous studies $(23-25)$ that, only when the glass bead content is $10 \mathrm{vol} \%$, will the process zone size of $0.5-\mathrm{LG} / 661$ be larger than that of LG/661. (The third possible explanation can also answer the question why the differences in cavity size and fracture toughness are found only in $10 \mathrm{vol} \%$ glass bead systems (Fig. 2).) As more CTBN is added into these two glass bead filled epoxies, the major micro-mechanical deformation mechanism changes from micro-shear banding to cavitation/shear yielding. When micro-shear banding is the major energy dissipation mechanism, it will govern the change of the fracture resistance of materials (R) with the increase of fracture surface (A), which determines the process zone size with the change of energy release rate $(G)$. (Process zone ranges from an initial crack tip to the onset point of unstable crack propagation. Instability in crack propagation occurs when the following two requirements are met: $\mathrm{G}-\mathrm{R} \geq 0$ and $\mathrm{dG} / \mathrm{dA}$ $>\mathrm{dR} / \mathrm{dA}(36)$.$) On the other hand, when cavitation/$ shear yielding is the major mechanism, it will determine the change of $\mathrm{R}$. Under this circumstance, the amount of CTBN will be more important than the types of glass beads, i.e. encapsulated or non-encapsulated. In fact, above about 3 phr CTBN content in Fig. 13. there is no difference in process zone size due to the encapsulation of glass beads. By contrast, below $3 \mathrm{phr}$, there is a distinct difference between encapsulated and non-encapsulated systems. Accordingly, as can be seen in Fig. 13, all the data in this Figure can be divided into two groups: glass bead dominant and CTBN dominant.

It was found in Figs. 1, 3, and 6 that fracture toughness was higher and CTBN cavities were larger in encapsulated systems than in non-encapsulated systems below 3 phr CTBN content. Now, this result can be explained by using the process zone size data. Below 3 phr (glass bead dominant group), process zone size is larger in encapsulated systems as explained above. Therefore, more cavitation/shear yielding mechanism of CTBN can occur and develop more during the stable sub-critical crack growth in the process zone, resulting in the higher fracture toughness in encapsulated systems. Since the CTBN content is relatively low (below 3 phr), the difference in fracture toughness caused by the different process zone size is only noticeable.

In the above discussion, the influence of CTBN particles on the fracture toughness of hybrid composites is considered small but significant in the glass bead dominant groups. Although process zone size is not a cause but a result of the fracture resistance of materials, the analysis of process zone size can provide possible explanations for the interactions between two tougheners, and the relationship between the interactions and the fracture toughness of composites.
The fracture toughness of hybrid-particulate composites can reflect the process zone size in all cases. Fig. 14 clearly shows this relationship: $\mathrm{K}_{\mathrm{IC}}$ is directly proportional to process zone size. This plot is a contrast to references 23-25, which shows no correlation between the $\mathrm{K}_{\mathrm{IC}}$ and the debonding zone size of glass bead filled epoxies. For example, 10 vol\% 0.5-LG/661 have larger debonding zone size than 10 vol\% LG/661. However, both the epoxies have the same fracture toughness (23-25).

\section{CONCLUSIONS}

As an attempt to improve toughness and modulus of epoxy resin, hybrid-particulate composites based on glass beads, CTBN, epoxy were prepared and their fracture behavior was studied. Two types of glass beads were prepared and used in the composites: one cleaned with distilled water (non-encapsulated) and the other encapsulated with a cured rubber. Successful toughening without losing modulus was achieved by limiting the content of CTBN below 7 phr. Overall toughness was found to be not a simple sum of two contributions, but a result of interplay between their compositions and microstructures. By introducing a rubber interlayer between glass beads and matrix, the fracture behavior of the hybrid-particulate composites and subsequently the interaction between glass beads and CTBN particles could be changed. This effect was evidently reflected in different degrees of CTBN cavitation in the hybrid-particulate composites.

By increasing the content of a toughener, the micromechanical deformations triggered by the toughener became more dominant. Thus, according to the relative contents and toughening effects of tougheners,

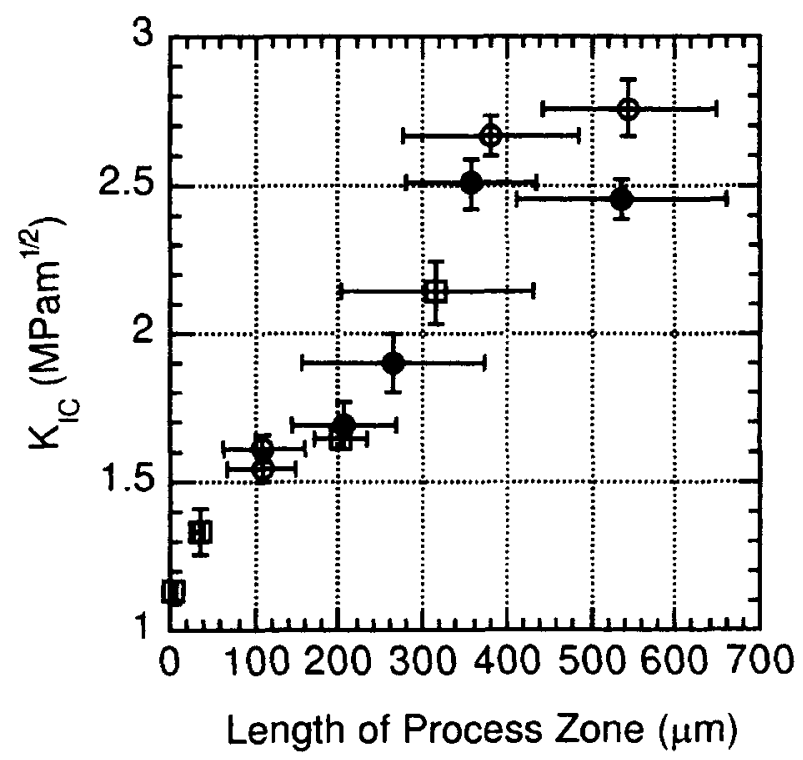

Fig. 14. Critical stress intensity factors versus process zone size in hybrid-particulate composites: $\square$ CTBN/661, O $26 \mathrm{phr}$ $L G / C T B N / 661$. 26 phr 0.5-LG/CTBN/661. 
our composites could be divided into two groups, i.e., glass bead dominant and CTBN dominant groups. As CTBN content increased in hybrid-particulate composites, the major micro-mechanical deformation mechanism found at the crack tip changed from micro-shear banding to cavitation of CTBN particles, and matrix shear yielding triggered by the cavitation. In encapsulated systems, this transition of the major deformation occurred at a lower CTBN content than in non-encapsulated systems. The existence of glass beads was observed to enhance the cavitation/shear yielding mechanism.

\section{ACKNOWLEDGMENTS}

This work was supported by the Specialized Materials Science Research Center of National Institute of Health (NIH), under a contract No. DEO 9296-09. Authors would like to thanks Dr. Jimmy Kishi, Dr. Jack Huang, and Jacqueline M. Denoyer for their help.

\section{REFERENCES}

1. R. Rothon, Particulate-filled Polymer Composites, Longman Scientific \& Technical (1995).

2. A. J. Kinloch and R. J. Young, Fracture Behavior of Polymers, Elsevier Applied Science (1985).

3. C. B. Bucknall, Toughened Plastics, Applied Science, London (1977).

4. L. Nicolais, E. Drioli, and R. F. Landel, Polymer, 14, 21 (1973).

5. A. J. Kinloch, D. L. Maxwell, and R. J. Young, J. Mater. Sci. 20, 4169 (1985).

6. B. Budiansky, J. C. Amazigo, and A. G. Evans, J. Mech Phys. Solids, 36, 167 (1988).

7. A. G. Evans, Z. B. Ahmad, D. G. Gilbert, and P. W. R. Beaumont, Acta Metall, 34, 79 (1986).

8. A. C. Moloney, H. H. Kausch, T. Kaiser, and H. R. Beer, J. Mater. Sci, 22, 381 (1987).

9. A. Maazouz, H. Sautereau, and J. F. Gerard, J. Appl. Polym. Sci, 50, 615 (1993).

10. H. Zhang and L. A. Berglund, Polym. Eng. Sci, 38, 100 (1993).

11. F. Martinatti and T. Ricco, J. Mater. Sci., 29, 442 (1994).

12. H. R. Azimi, R. A. Pearson, and R. W. Hertzberg, Polym. Eng. Sci., 36, 2352 (1996).

13. F. F. Lange, Phil. Mag., 22, 983 (1970).

14. A. G. Evans, Phil. Mag., 26, 1327 (1972).
15. D. J. Green, P. S. Nicholson, and J. D. Embury, J. Mater. Sci, 12, 987 (1977), Ibid., 14, 1413 (1979), Ibid., 14, 1657 (1979).

16. J. R. Rice, Y. Ben-Zion, and K. Kim, J. Mech. Phys. Solids, 42, 813 (1994).

17. D. Li, A. F. Yee, I,-W. Chen, S.-C. Chang, and K. Takahashi, J. Mater. Sci, 28, 2205 (1994).

18. A. F. Yee, D. Li, and X. Li, J. Mater. Sci., 28, 6392 (1993).

19. A. F. Yee and R. A. Pearson, J. Mater. Sci, 21, 2462 (1986).

20. R. A. Pearson and A. F. Yee, J. Mater. Sci, 21, 2475 (1986).

21. R. A. Pearson and A. F. Yee, J. Mater. Sci, 24, 2571 (1989).

22. R. A. Pearson and A. F. Yee, J. Mater. Sci., 26, 3828 (1991).

23. J. Lee, $\mathrm{PhD}$ thesis, The University of Michigan (1998).

24. J. Lee and A. F. Yee, Polym. Prepr., Am. Chem. Soc. Div. Polym. Chem., 38, 369 (1997); Polym. Prepr., Am. Chem. Soc. Div. Polym. Mater., 39, 200 (1998).

25. J. Lee and A. F. Yee, Polymer, in press.

26. J. Hilborn, J. Bidaux, and J. E. Manson, Polym Prepr., Am. Chem. Soc. Div. Polym. Mater, 34, 639 (1993).

27. C. Scott, H. Ishida, and F. H. J. Maurer, J. Mater. Sci, 22, 3963 (1987).

28. J. Kolarik and J. Jancar. Polymer, 33, 4961 (1992).

. 29. J. Jancar and A. T. Dibenedetto, J. Mater. Sci., 29 , 4651 (1994).

30. D. Benderly, A. Siegmann, and M. Narkis, Polymer Composites, 17, 86 (1996).

31. B. Pukanszky, F. Tudos, J. Kolarik, and F. Lednicky, Polym. Compos., 11, 98 (1990).

32. J. Kolarik, F. Lednicky, J. Jancar, and B. Pukanszky, Polym. Comm, 31, 201 (1990).

33. Y. G. Lin, J. F. Gerard, J. Y. Cavaille, H. Sautereau, and J. P. Pascault, Polym. Bull, 17, 97 (1987).

34. N. Amdouni, H. Sautereau, and J. Gerard, J. Appl. Polym. Sci, 45, 1799 (1992), Ibid., 46, 1723 (1992).

35. R. W Hertzberg, Deformation and Fracture Mechanics of Engineering Materials, John Wiley and Sons, New York (1989).

36. J. G. Williams, Fracture Mechanics of Polymers, 1st Ed., Ellis Horwood Limited (1984).

37. S. Y. Hobbs and V. H. Watkins, J. Polym. Sci. B, 20. 651 (1982).

38. A. S. Holik, R. P. Kambour, S. Y. Hobbs, and D. G. Fink, Microstruct. Sci, 7, 367 (1979).

39. V. A. Matonis and N. C. Small, Polym. Eng. Sci., 8, 90 (1969).

40. G.-M. Kim and G. H. Michler, Proc. of 36th IUPAC Int. Symp. on Macromolecules, IUPAC MACRO Seoul 1996, Seoul, Korea (1996). 